\title{
A New Bidirectional Associative Neutrosophic Cognitive Dynamical System approaches to study Youth Violence
}

\author{
A. Victor Devadoss \\ Head \& Associate Professor \\ PG \& Research Department of mathematics \\ Loyola College, Chennai-34, India
}

\author{
A. Felix \\ Ph.D. Research scholar \\ PG \& Research Department of mathematics \\ Loyola College, Chennai-34, India
}

\begin{abstract}
BAM and NCMs have been applied in many fields to show the relationship between the essential components. In this paper we introduce a new Neutrosophic Bimodal called Bidirectional Associative Neutrosophic Cognitive Maps (BANCMs) to analyze the problem of youth violence since enormous growth of violent escalation among youth in every country and culture is alarming. This new model can act simultaneously to give the solution in more accurately. This article organized as follows, section one describes the problem of our study. Section two recalls the basic concepts of BAM and NCM. Section three gives the new modal BANCM. Section four, the adaptation of the problem using BANCM and final section derived conclusion, suggestion and scope for future study.
\end{abstract}

Keywords: BAM, NCM, BANCM, fixed point, limit cycle, bihidden pattern.

\section{INTRODUCTION}

Cognitive maps were initially introduced by Robert Axelrod [1] in 1976. He used this modal to study decision making in social and political systems. Bart Kosco enhanced the power of cognitive maps considering fuzzy values for the concepts of the cognitive map and fuzzy degrees of interrelationships between concepts [2]. In 2003, NCM was introduced by W.B.Vasanhakandasamy and Florentin Samaranche to study the aspects of migrant laborers living with HIV/AIDS [7]. The BAM modal was introduced by Bart Kosco in 1988 and modified in the year 2001[3]. Praveen prakash has introduced a bimodal called Fuzzy Cognitive Relational Maps (FCRM) in the year 2010. Thirusangu et.al 2012 introduced a Bimodal Called Bidirectional Associative Fuzzy Cognitive maps (BACM) [6]. In this paper we introduce a new BANCM modal by combining BAM and NCM since to connect the attributes there is an indeterminate occurs. This model work simultaneously to study the problem of youth violence. Violence among young people is one of the most visible forms of violence. Both fatal and non-fatal assaults involving young people contribute greatly to the burden of premature death, injury and disability. Youth violence deeply harms not only its victims, but also their families, friends and communities. An average of 565 children, adolescents and young adults between the ages of 10 and 29 years die each day as a result of interpersonal violence across the world says the World Report on Violence and Health,2002. A large number of these are from the South-East Asia Region. And also enormous growth of violent escalation among youth in every country and culture is alarming. With this background of information the study was conducted to assess the causes and effect of youth violence. Moreover the data is an unsupervised one obtained from survey as well as interviews. We have got two sets of attributes by the two different experts, in which one relates to the BAM dynamical system and other with a NCM dynamical system and if we wish to see the stage-by-stage effect of the attributes on the system, we need a dynamical system. Hence we introduce a dynamical bisystem

\section{THEORITICAL BACKGROUND}

\subsection{BAM MODEL}

A group of neurons forms a field. Neural networks contain many fields of neurons. $F_{x}$ denotes a neuron field which contains $n$ neurons and $F_{y}$ denotes a neuron field which contains p neurons.

Neuronal Dynamical Systems: The neuronal dynamical system is described by a system of first order differential equations that govern the time evaluation of the neuronal activations or membrane potentials.

$\dot{X}_{i}=g_{i}(X, Y, \ldots), \dot{Y}_{i}=h_{j}(X, Y, \ldots)$

where $\mathrm{x}_{\mathrm{i}}$ and $\mathrm{y}_{\mathrm{j}}$ denote respectively the activation time function of the $i^{\text {th }}$ neuron in $F_{x}$ and the $j^{\text {th }}$ neuron in $F_{y}$. The over dot denotes time differentiation, $\mathrm{g}_{\mathrm{i}}$ and $\mathrm{h}_{\mathrm{j}}$ are functions of $\mathrm{X}, \mathrm{Y}$ etc., where $\mathrm{X}(t)=\left(\mathrm{x}_{1}(t), \ldots \ldots ., \mathrm{x}_{\mathrm{n}}(t)\right), \quad \mathrm{Y}(t)=$ $\left(\mathrm{y}_{1}(t), \ldots \ldots, \mathrm{y}_{\mathrm{n}}(t)\right)$

Define the state of the neuronal dynamical system at time $t$. Additive bivalent Models describe asynchronous and stochastic behavior. At each moment each neuron can randomly decide whether to change state, or whether to omit a new signal given its current activation. The BAM is a nonadaptive, additive, bivalent neural network.

\subsubsection{Bivalent Additive BAM}

In neural literature, the discrete version of the earlier equations is often referred to as the Bidirectional Associative Memories or BAMs. A discrete additive BAM with threshold signal functions, arbitrary thresholds and inputs, an arbitrary but a constant synaptic connection matrix $\mathrm{M}$ and discrete time steps $\mathrm{K}$ are defined by the equations.

$$
\begin{aligned}
x_{i}^{k+1} & =\sum_{j}^{p} S_{j}\left(y_{j}^{k}\right) m_{i j}+I_{i} \\
y_{j}^{k+1} & =\sum_{i}^{n} S_{i}\left(y_{i}^{k}\right) m_{i j}+I_{j}
\end{aligned}
$$

Where, $m_{i j} \in M \quad \mathrm{~S}_{\mathrm{i}}$ and $\mathrm{S}_{\mathrm{j}}$ are the signal functions. They represent binary or bipolar threshold functions. For arbitrary real-valued thresholds $\mathrm{U}=\left(\mathrm{U}_{1}, \mathrm{U}_{2} \ldots, \mathrm{U}_{\mathrm{n}}\right)$ for $\mathrm{F}_{\mathrm{x}}$ neurons and $\mathrm{V}=\left(\mathrm{V}_{1}, \mathrm{~V}_{2} \ldots, \mathrm{V}_{\mathrm{n}}\right)$ for $\mathrm{F}_{\mathrm{y}}$ neurons. The threshold binary signal functions corresponds neurons. 


\subsubsection{Synaptic connection Matrices}

Let us suppose that the field $F_{x}$ with $n$ neurons is synaptic ally connected to the field $\mathrm{F}_{\mathrm{y}}$ with $p$ neurons. Let $\mathrm{m}_{\mathrm{ij}}$ be a synapse where the axon from the $\mathrm{i}^{\text {th }}$ neuron in $\mathrm{F}$ terminates, $\mathrm{m}_{\mathrm{ij}}$ can be positive, negative or zero. The synaptic matrix $\mathrm{M}$ is a $n \times p$ matrix of real numbers whose entries are the synaptic efficacies $m_{i j}$. The matrix $M$ describes the forward projections from the neuronal field $\mathrm{F}_{\mathrm{x}}$ to the neuronal field $\mathrm{F}_{\mathrm{y}}$. Similarly, $\mathrm{M}^{\mathrm{T}}$, a $p \times \mathrm{n}$ synaptic matrix and describes the backward projections $\mathrm{F}_{\mathrm{y}}$ to $\mathrm{F}_{\mathrm{x}}$.

\subsubsection{Unidirectional Networks}

These kinds of networks occur when a neuron synoptically interconnects to itself. The matrix $\mathrm{N}$ is $\mathrm{n} \mathrm{x} \mathrm{n}$ square matrix.

\section{Bidirectional Networks.}

A network is said to be a bidirectional network if $\mathrm{M}=\mathrm{N}^{\mathrm{T}}$ and $\mathrm{N}=\mathrm{M}^{\mathrm{T}}$

\subsubsection{Bidirectional Associative Memories}

When the activation dynamics of the neuronal fields $F_{x}$ and $F_{y}$ lead to the overall stable behavior, the bi-directional networks are called as Bi-directional Associative Memories or BAM. A unidirectional network also defines a BAM if M is symmetric i.e. $M=M$. In the next section, we proceed on to give more details about this BAM.

\subsubsection{Additive Activation Models}

An additive activation model is defined by a system of $n+p$ coupled first-order differential equations that interconnects the fields $F_{x}$ and $F_{y}$ through the constant synaptic matrices $M$ and $\mathrm{N}$ described earlier. $\mathrm{S}_{\mathrm{i}}\left(\mathrm{x}_{\mathrm{i}}\right)$ and $\mathrm{S}_{\mathrm{j}}\left(\mathrm{y}_{\mathrm{j}}\right)$ denote respectively the signal function of the $i^{\text {th }}$ neuron in the field $F_{x}$ and the signal function of the $j^{\text {th }}$ neuron in the field $F_{y}$. Discrete additive activation models correspond to neurons with threshold signal functions. The neurons can assume only two values $\mathbf{O N}$ and $\mathbf{O F F}$. On represents the signal value +1 and OFF represents 0 or -1 ( -1 when the representation is bipolar). The bipolar version of these equations yield the signal value -1 when $\mathrm{x}_{\mathrm{i}}<\mathrm{U}_{\mathrm{i}}$ or $\mathrm{y}_{\mathrm{j}}<\mathrm{V}_{\mathrm{j}}$.

$$
\begin{aligned}
& \dot{x}=-A_{i} x_{i}+\sum_{j}^{p} S_{j}\left(y_{j}^{k}\right) m_{j i}+I_{i} \\
& \dot{y}=-A_{j} y_{j}+\sum_{i}^{n} S_{i}\left(y_{i}^{k}\right) m_{i j}+I_{j}
\end{aligned}
$$

The bivalent signal functions allow us to model complex asynchronous state-change patterns. At any moment different neurons can decided whether to compare their activation to their threshold. A each moment any of the $2^{n}$ subsets of $F_{x}$ neurons or the $2^{\mathrm{p}}$ subsets of the $\mathrm{F}_{\mathrm{y}}$ neurons can decide to change state. Each neuron may randomly decide whether to check the threshold conditions in the equations given above.

At each moment each neuron defines a random variable that can assume the value $\mathrm{ON}(+1)$ or OFF $(0$ or -1$)$. The network is often assumed to be deterministic and state changes are synchronous ie an entire field of neurons is updated at a time. In case of simple asynchrony only one neuron makes a state change decision at a time. When the subsets represent the entire fields $F_{x}$ and $F_{y}$ synchronous state change results.

In a real life problem the entries of the constant synaptic matrix $M$ depends upon the investigator's feelings. The synaptic matrix is given a weight age according to their feelings. If $x \quad F_{x}$ and $y F_{y}$ the forward projections from $F_{x}$ to $\mathrm{F}_{\mathrm{y}}$ is defined by the matrix M.: $\left\{\mathrm{P}\left(\mathrm{x}_{\mathrm{I}}, \mathrm{x}_{\mathrm{j}}\right)\right\}=\mathrm{M}, 1<\mathrm{I}<\mathrm{n}, 1<\mathrm{j}<\mathrm{p}$.
The backward projection is defined by the Matrix $\mathrm{M}^{\mathrm{T} .}:\left\{\mathrm{F}\left(\mathrm{y}_{\mathrm{j}}, \mathrm{x}_{\mathrm{I}}\right)\right\}=\left(\mathrm{m}_{\mathrm{ij}}\right)=\mathrm{M}^{\mathrm{T}}, 1<\mathrm{I}<\mathrm{n}, \mathrm{I}<\mathrm{j}<\mathrm{p}$.

\subsubsection{Bidirectional Stability}

All BAM state changes lead a fixed-point stability. This property holds for synchronous as well as asynchronous state changes.

A BAM system $\left(F_{x}, F_{y}, M\right)$ is bidirectionally stable if all inputs converge to fixed pint equilibrium. Bidirectional stability is a dynamic equilibrium. The same signal information flows back and forth in a bidirectional fixed point.

Let us suppose that A denotes a binary n-vector and B denotes a binary p-vector. Let $\mathrm{A}$ be initial input to the BAM system. Then the BAM equilibrates a bi directional fixed point $\left(\mathrm{A}_{\mathrm{i}} \mathrm{B}_{\mathrm{j}}\right)$ as

$$
\begin{aligned}
& A \rightarrow M \rightarrow B \\
& A^{\prime} \leftarrow M^{T} \leftarrow B \\
& A^{\prime} \rightarrow M \rightarrow B^{\prime} \\
& A^{\prime \prime} \leftarrow M^{T} \leftarrow B^{\prime} \\
& \cdots \\
& A_{\mathrm{f}} \rightarrow M \rightarrow B_{\mathrm{f}} \\
& A_{\mathrm{f}} \leftarrow M^{T} \leftarrow B_{\mathrm{f}}
\end{aligned}
$$

Where $\mathrm{A}^{\prime}, \mathrm{A}^{\prime \prime} \ldots$ and $\mathrm{B}^{\prime}, \mathrm{B}^{\prime \prime} \ldots$ represents intermediate or transient signal state vectors between $A$ and $A_{f}, B$ and $B_{f}$. respectively. The fixed point of a bidirectional system is time dependent. The fixed point for the initial input vectors can be attained at different times which are illustrated later. Based on the synaptic matrix $M$ which is developed by the investigators feelings, the time at which bi directional stability is attained also varies accordingly

\subsection{NEUTROSOPHIC COGNITIVE MAPS}

Fuzzy Cognitive Maps (FCMs) are more applicable when the data in the first Place is an unsupervised one. The FCMs work on the opinion of experts. FCMs model the world as a collection of classes and causal relations between classes.

\subsubsection{Definition}

When the nodes of the NCM are fuzzy sets then they are called as fuzzy nodes.

\subsubsection{Definition}

NCMs with edge weights or causalities from the set $\{-1,0,1$, I\} are called simple NCMs

\subsubsection{Definition}

Let $\mathrm{C}_{\mathrm{i}}$ and $\mathrm{C}_{\mathrm{j}}$ denote the two nodes of the NCM. The directed edge from $C_{i}$ to $C_{j}$ denote the causality of $C_{i}$ on $C_{j}$ called connections. Every edge in the NCM is weighted with a number in the set $\{-1,0,1, \mathrm{I}\}$. Let $\mathrm{e}_{\mathrm{ij}}$ be the weight of the directed edge $\mathrm{C}_{\mathrm{i}} \mathrm{C}_{\mathrm{j}}, \mathrm{e}_{\mathrm{ij}} \in\{.1,0,1, \mathrm{I}\} . \mathrm{e}_{\mathrm{ij}}=0$ if $\mathrm{C}_{\mathrm{i}}$ does not have any effect on $\mathrm{C}_{\mathrm{j}}, \mathrm{e}_{\mathrm{ij}}=1$ if increase (or decrease) in $\mathrm{C}_{\mathrm{i}}$ causes increase (or decreases) in $\mathrm{C}_{\mathrm{j}} . \mathrm{e}_{\mathrm{ij}}=1$ if increase (or decrease) in $C_{i}$ causes decrease (or increase) in $C_{j} e_{i j}=I$ if the relation or effect of $\mathrm{C}_{\mathrm{i}}$ on $\mathrm{C}_{\mathrm{j}}$ is an indeterminate.

\subsubsection{Definition}

Let $\mathrm{C}_{1} \mathrm{C}_{2}, \ldots, \mathrm{C}_{\mathrm{n}}$ be nodes of a NCM. Let the neutrosophic matrix $N(E)$ be defined as $N(E)=\left(e_{i j}\right)$ where $e_{i j}$ is the weight of 
the directed edge $C_{i} C_{j}$, where $e_{i j} \in\{.1,0,1, I\}$. N (E) is called the neutrosophic adjacency matrix of the NCM.

\subsubsection{Definition}

Let $\mathrm{C}_{1}, \mathrm{C}_{2}, \ldots, \mathrm{C}_{\mathrm{n}}$ be the nodes of the NCM. Let $\mathrm{A}=$ $\left\{a_{1}, a_{2} \ldots a_{n}\right\}$, where $a_{i} \in\{0,1, I\}$. A is called the instantaneous state neutrosophic vector and it denotes the ON-OFFINDETERMINATE state position of the node at an instant

$a_{i}=0$ if $a_{i}$ is OFF (no effect)

$a_{i}=1$ if $a_{i}$ is ON (has effect)

$\mathrm{a}_{\mathrm{i}}=\mathrm{I}$ if $\mathrm{a}_{\mathrm{i}}$ is INDETERMINATE (effect cannot be determined) for $\mathrm{i}=1,2, \ldots, \mathrm{n}$

\subsubsection{Definition}

Let $C_{1} C_{2}, \ldots, C_{n}$ be the nodes of the FCM. Let $C_{1} C_{2}, C_{2} C_{3} \ldots C_{i} C_{j}$ be the edges of the NCM. Then the edges form a directed cycle. An NCM is said to be cyclic if it possesses a directed cyclic. An NCM is said to be acyclic if it does not possess any directed cycle.

\subsubsection{Definition}

An NCM with cycles is said to have a feedback. When there is a feedback in the NCM i.e. when the causal relations flow through a cycle in a revolutionary manner the NCM is called a dynamical system.

\subsubsection{Definition}

Let $C_{1} C_{2}, C_{2} C_{3} \ldots C_{n-1} C_{n}$ be cycle, when $\mathrm{C}_{\mathrm{i}}$ is switched on and if the causality flow through the edges of a cycle and if it again causes $C_{i}$, we say that the dynamical system goes round and round. This is true for any node $C_{i}$, for $i=1,2, \ldots, n$ the equilibrium state for this dynamical system is called the hidden pattern.

\subsubsection{Definition}

If the equilibrium state of a dynamical system is a unique state vector, then it is called a fixed point. Consider the NCM with $\mathrm{C}_{1} \mathrm{C}_{2}, \ldots, \mathrm{C}_{9}$ as nodes. For example let us start the dynamical system by switching on $\mathrm{C}_{1}$ Let us assume that the NCM settles down with $C_{1}$ and $C_{n}$ on, i.e. the state vector remain as $(1,0, ., 1)$ this neutrosophic state vector $(1,0, ., 0,1)$ is called the fixed point.

\subsubsection{Definition}

If the NCM settles with a neutrosophic state vector repeating in the form $A_{1} \rightarrow A_{2} \rightarrow \ldots A_{i} \rightarrow A_{1}$ then this equilibrium is called a limit cycle of the NCM

\section{The New BANCM Bimodal 3.1 Definition}

Let $A=A_{1} \cup A_{2}$ where $A_{1}$ and $A_{2}$ are non-empty sets; with $\mathrm{A}_{1} \mathrm{~A}_{2}$ and $\mathrm{A}_{1} \mathrm{~A}_{2}$ then we call $\mathrm{A}$ as a biset.

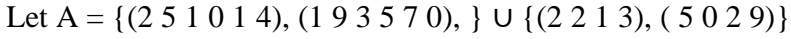

$=\mathrm{A}_{1} \cup \mathrm{A}_{2}$, clearly $\mathrm{A}$ is a biset.

\subsection{Definition}

Let $\mathrm{V}_{1}=\left(\mathrm{v}_{1}, \mathrm{v}_{2} \ldots \mathrm{v}_{\mathrm{n}}\right), \mathrm{V}_{2}=\left(\mathrm{v}_{1}, \mathrm{v}_{2}, \mathrm{v}_{3}, \ldots, \mathrm{v}_{\mathrm{m}}{ }^{\prime}\right)$ be two vectors of length $n$ and $m$ respectively. Then $\mathrm{V}=\mathrm{V}_{1} \mathrm{UV}_{2}$ is a neutrosophic bivector.
Let $\mathrm{V}=\mathrm{V} 1 \mathrm{U} \mathrm{V} 2=\left(\begin{array}{lllll}6 & 5 & 2 \mathrm{I} & 1 & 3 \mathrm{I}\end{array}\right) \mathrm{U}\left(\begin{array}{llll}3 & 4 \mathrm{I} & 5 & 1\end{array}\right), \mathrm{V}$ is a neutrosophic bivector.

\subsection{Definition:}

A matrix $E$ is said to be a Neutrosophic bimatrix. If $E=E_{1} U$ $E_{2}$ where $E_{1}$ and $E_{2}$ are two different matrices.

$$
\mathrm{E}=\left[\begin{array}{ccc}
4 & I & 2 \\
2 I & 6 & 3 \\
0 & 7 & 5 I
\end{array}\right] \cup\left[\begin{array}{ccc}
1 & I & 41 \\
2 I & 6 & 73 \\
0 & 7 & 1 I
\end{array}\right]
$$

\subsection{Definition}

Let $\mathrm{G}=\mathrm{G}_{1} \cup \mathrm{G}_{2}$ where $\mathrm{G}_{1}$ and $\mathrm{G}_{2}$ are two distinct graphs then we call $\mathrm{G}$ as a bigraph.

\subsection{Definition}

Let $\mathrm{E}=\mathrm{E}_{1} \mathrm{U} \mathrm{E}_{2}$ be a neutrosophic bimatrix. Then the bitranspose of the bimatrix $E$ is defined as $E^{t}=\left(E_{1} \cup E_{2}\right)^{t}=$ $E_{1}^{\mathrm{t}} \cup \mathrm{E}_{2}^{\mathrm{t}}$

\subsection{Definition}

A Bidirectional Associative Neutrosophic Cognitive Maps (BANCM) is a directed special bigraph with concepts like policies, events, etc as nodes and causalities as edges. It represents causal relationship between concepts. In a BANCM we call the pair of associated nodes as binodes. If the order of the bimatrix associated with BAFCM is a $p \times m$ matrix and a $n \times n$ square matrix then the binodes are bivectors of length $(p, n)$ or $(m, n)$.

\subsection{Definition}

Consider the binodes biconcepts $\left\{\mathrm{X}_{1}, \ldots \mathrm{X}_{\mathrm{p}}\right\}$ and $\left.\left\{\mathrm{Y}_{1} \ldots \mathrm{Y}_{\mathrm{m}}\right\}\right\}$ of the BAM and $\left\{\mathrm{C}_{1}, \mathrm{C}_{2} \ldots . \mathrm{C}_{\mathrm{n}}\right\}$ of the NCM of the BANCM bimodel. Suppose the directed graph is drawn using the edge biweight $\mathrm{e}_{\mathrm{ij}}{ }^{1}=[-5,5] ; \quad \mathrm{e}_{\mathrm{ij}}{ }^{2}=[-1,1], \quad \mathrm{I}$. The bimatrix $\mathrm{E}=\mathrm{E}_{1} \cup \mathrm{E}_{2}$ is defined by $\mathrm{e}_{\mathrm{ks}}{ }^{1} \cup \mathrm{e}_{\mathrm{ij}}{ }^{2}$ where $\mathrm{e}_{\mathrm{ks}}{ }^{1}$ is the directed edge of $X_{k} Y_{s}$ and $e_{i j}{ }^{2}$ is the weight of the directed edge $C_{i} C_{j}$. $\mathrm{E}=\mathrm{E}_{1} \mathrm{U} \mathrm{E}_{2}$ is called adjacency bimatrix of the new BANCM bimodal.

\subsection{Definition}

The new BANCMs with edge biweight $\{1,0,-1, \mathrm{I}\}$ are called simple BANCMs. Let $\left\{\left(\mathrm{X}_{1}, \ldots \mathrm{X}_{\mathrm{m}}\right),\left(\mathrm{Y}_{1} \ldots \mathrm{Y}_{\mathrm{n}}\right)\right\} \cup\left\{\mathrm{C}_{1}, \ldots \mathrm{C}_{\mathrm{p}}\right\}$ be the binodes of an BANCM. $\mathrm{V}=\mathrm{V}_{1} \cup \mathrm{V}_{2}=\left(\mathrm{x}_{1}, \ldots \mathrm{x}_{\mathrm{m}}\right)$ $\left(\operatorname{or}\left(\mathrm{y}_{1}, \ldots \mathrm{y}_{\mathrm{n}}\right)\right) \cup\left(\mathrm{z}_{1}, \ldots \mathrm{z}_{\mathrm{p}}\right)$, where $\mathrm{x}_{\mathrm{i}}, \mathrm{y}_{\mathrm{j}}, \mathrm{z}_{\mathrm{k}} \in\{0,1 . \mathrm{I}\} ; 1 \leq \mathrm{i} \leq \mathrm{m}$, $1 \leq \mathrm{j} \leq \mathrm{n}$ and $1 \leq \mathrm{k} \leq \mathrm{p}$. V is called instantaneous state bivector and it denotes the ON-OFF-INDETERMINATE position of the node at an instant.

$$
\begin{aligned}
\mathrm{x}_{\mathrm{j}} & =0, \mathrm{y}_{\mathrm{i}}=0, \mathrm{z}_{\mathrm{k}}=0 \text { if } \mathrm{x}_{\mathrm{j}}, \mathrm{y}_{\mathrm{i}}, \mathrm{z}_{\mathrm{k}} \text { are OFF, } \\
\mathrm{x}_{\mathrm{j}} & =1, \mathrm{y}_{\mathrm{i}}=1, \mathrm{z}_{\mathrm{k}}=1 \text { if } \mathrm{x}_{\mathrm{j}}, \mathrm{y}_{\mathrm{i}}, \mathrm{z}_{\mathrm{k}} \text { are ON } \\
\mathrm{x}_{\mathrm{j}} & =\mathrm{I}, \mathrm{y}_{\mathrm{i}}=\mathrm{I}, \mathrm{z}_{\mathrm{k}}=\mathrm{I} \text { if } \mathrm{x}_{\mathrm{j}}, \mathrm{y}_{\mathrm{i}}, \mathrm{z}_{\mathrm{k}} \text { are Indeterminate for } \\
1 \leq \mathrm{j} \leq m, 1 & \leq \mathrm{i} \leq n \text { and } 1 \leq k \leq p
\end{aligned}
$$

\subsection{Definition}

Let $\left\{\left(\mathrm{X}_{1}, \ldots \mathrm{X}_{\mathrm{m}}\right),\left(\mathrm{Y}_{1} \ldots \mathrm{Y}_{\mathrm{n}}\right)\right\} \cup\left\{\mathrm{C}_{1}, \ldots \mathrm{C}_{\mathrm{p}}\right\}$ be the binodes of an BANCM.. Let $X_{k} Y_{s} \cup C_{i} C_{j}$ be the biedges of the BANCMs; $1 \leq k \leq m, 1 \leq s \leq n, 1 \leq \mathrm{i}, \mathrm{j} \leq p,(\mathrm{i} \neq \mathrm{j})$. Then the biedges form a directed bicycle. A BANCM is said to be bicyclic if it possesses a directed bicycle. An BANCM is said to be a bicyclic if it does not possess any directed bicycle.

Example: 


\subsection{Definition}

A BAFCM with bicycles is said to have a feedback. When there is a feed back in an BAFCM, i.e., when the casual relations flow through a cycle in a revolutionary way, the BAFCM is called a dynamical bisystem.

\subsection{Definition}

If the $\mathrm{BAFCM}$ settles down with a bistate, bivector repeating in the form $\mathrm{B}_{1} \rightarrow \mathrm{B}_{2} \rightarrow \ldots . . \mathrm{B}_{\mathrm{j}} \rightarrow \mathrm{B}_{1}$ ( or $\mathrm{D}_{1} \rightarrow \mathrm{D}_{2} \rightarrow \ldots \rightarrow \mathrm{D}_{\mathrm{k}} \rightarrow \mathrm{D}_{1}$ ) $\mathrm{U}$ $\mathrm{A}_{1} \rightarrow \mathrm{A}_{2} \rightarrow \ldots . . \mathrm{A}_{1}$ then this equilibrium is called a limit bicycle.

\subsection{Definition}

The biedges $\mathrm{e}_{\mathrm{ij}}=\left(\mathrm{e}_{\mathrm{ks}}^{1}\right) \cup\left(\mathrm{e}_{\mathrm{ij}}^{2}\right)$ take the values in fuzzy causal biinterval[-1,1] $\cup[-1,1] \cup \mathrm{I}$.

i) $\mathrm{e}_{\mathrm{ij}}=0$ indicates no causality between the binodes.

ii) $\mathrm{e}_{\mathrm{ij}}>0$ implies that both $\mathrm{e}_{\mathrm{ij}}{ }^{2}>0$ and $\mathrm{e}_{\mathrm{ks}}{ }^{1}>0$; implies increase in the binodes $C_{i} \cup X_{k}\left(\right.$ or $\left.Y_{s}\right)$; implies increase in the binodes $\mathrm{C}_{\mathrm{j}} \cup \mathrm{Y}_{\mathrm{s}}\left(\right.$ or $\left.\mathrm{X}_{\mathrm{s}}\right)$.

iii) $\mathrm{e}_{\mathrm{ij}}<0$ implies that both $\mathrm{e}_{\mathrm{ij}}{ }^{2}<0$ and $\mathrm{e}_{\mathrm{ks}}{ }^{1}<0$; similarly decrease in the binodes $\mathrm{C}_{\mathrm{i}} \cup \mathrm{X}_{\mathrm{k}}\left(\right.$ or $\left.\mathrm{Y}_{\mathrm{s}}\right)$; implies decrease in the binodes $\mathrm{C}_{\mathrm{j}} \cup \mathrm{Y}_{\mathrm{s}}\left(\right.$ or $\left.\mathrm{X}_{\mathrm{k}}\right)$

iv) ) $\mathrm{e}_{\mathrm{ij}}=\mathrm{I}$ indicates Indeterminate between the binodes However, unlike the NCM and BAM model we can have the following possibilities other than that of $\mathrm{e}_{\mathrm{ij}}=0, \mathrm{e}_{\mathrm{ij}}>0$ and $\mathrm{e}_{\mathrm{ij}}<0$.

i) $e_{i j}=\left(e_{i j}^{2}\right) \cup\left(e_{k s}^{1}\right)$ can be such that $\left(e_{i j}^{2}\right)=0$ and $\left(\mathrm{e}_{\mathrm{ks}}{ }^{1}\right)>0$. No relation in one binode and an increase in other node.

ii) $\mathrm{e}_{\mathrm{ij}}=\left(\mathrm{e}_{\mathrm{ij}}{ }^{2}\right) \cup\left(\mathrm{e}_{\mathrm{ks}}{ }^{1}\right)$ we can have $\left(\mathrm{e}_{\mathrm{ij}}{ }^{2}\right)=0$ and $\left(\mathrm{e}_{\mathrm{ks}}{ }^{1}\right)<0$. No causality in the NCM node and decreasing relation in the BAM mode.

iii) $\mathrm{e}_{\mathrm{ij}}=\left(\mathrm{e}_{\mathrm{ij}}^{2}\right) \cup\left(\mathrm{e}_{\mathrm{ks}}^{1}\right)$ we can have $\left(\mathrm{e}_{\mathrm{ij}}^{2}\right) \leq 0$ and $\left(\mathrm{e}_{\mathrm{ks}}^{1}\right)>0$
iv)In $\mathrm{e}_{\mathrm{ij}}=\left(\mathrm{e}_{\mathrm{ij}}{ }^{2}\right) \cup\left(\mathrm{e}_{\mathrm{ks}}^{1}\right)$ we can have $\left(\mathrm{e}_{\mathrm{ij}}{ }^{2}\right)<0$ and $\left(\mathrm{e}_{\mathrm{ks}}{ }^{\mathrm{i}}\right)=0$

v) In $\mathrm{e}_{\mathrm{ij}}=\left(\mathrm{e}_{\mathrm{ij}}{ }^{2}\right) \cup\left(\mathrm{e}_{\mathrm{ks}}^{1}\right)$ we can have $\left(\mathrm{e}_{\mathrm{ij}}{ }^{2}\right)>0$ and $\left(\mathrm{e}_{\mathrm{ks}} 1\right)=0$

vi) In $\mathrm{e}_{\mathrm{ij}}=\left(\mathrm{e}_{\mathrm{ij}}{ }^{2}\right) \cup\left(\mathrm{e}_{\mathrm{ks}}{ }^{1}\right)$ we can have $\left(\mathrm{e}_{\mathrm{ij}}{ }^{2}\right)>0$ and $\left(\mathrm{e}_{\mathrm{ks}}^{1}\right)<0$.

Thus in the case of BANCM we can have 9 possibilities where as in NCMs or BAMs we have only 4 possibilities. Thus the extra 6 possibilities can help in making the Solution of the problem more sensitive or accurate.

\section{ADAPTATION OF THE PROBLEM}

Youth violence is a devastating public health problem worldwide. According to the World Health Organization, over 540 adolescents and young adults die every day from interpersonal violence. Annually, anywhere from 3.5 to 7.5 million young people experience injuries from violence requiring hospital treatment. Indeed, the health consequences of violence are severe, including death, permanent physical disabilities, high costs of medical care and rehabilitation, and immeasurable grief and suffering.

To analyze the causes and effect of youth violence, we have interviewed and collected a data from 100 youth in and around Chennai. After that some of the data was transformed in to a BAM as 8 main attributes of causes of violence and 7 attributes as effect of violence. We list out briefly the main attributes given below

\section{Cause of youth violence:}

$\mathrm{A}_{1}$ - Poor family functioning

$\mathrm{A}_{2}$-Academic failure / dropping out of school
$\mathrm{A}_{3}$-Delinquent peers / gang membership

$\mathrm{A}_{4}$-Poverty in the community

$\mathrm{A}_{5}$-Castesam / inequality

$\mathrm{A}_{6}$-Influences of mass media

$\mathrm{A}_{7}$-Opportunities are denied

$\mathrm{A}_{8}$-Prizes hike in the basic needs

\section{Effects of youth violence:}

$\mathrm{B}_{1}$ - Audit for drugs and alcohol

$\mathrm{B}_{2^{-}}$Damage public property/ burning down Public transport

$\mathrm{B}_{3}$ - Involving in other forms of anti-social behavior such as terrorism, robbery etc.

$\mathrm{B}_{4^{-}}$Murdering / fake encounter

$\mathrm{B}_{5}$-Long drawn strike

$\mathrm{B}_{6}$-Run away from home

$\mathrm{B}_{7}$-Increasing aggressive behavior

Also through another expert the linguistic questionnaire was transformed in to NCM. In which 8 main attributes of youth violence is chosen, which are given below
$\mathrm{C}_{1}$ - Parental criminality / Domestic violence
$\mathrm{C}_{2}$ - Truancy and dropping out of school
$\mathrm{C}_{3}$ - Ill treatment by teacher
$\mathrm{C}_{4}$ - Bad Company
$\mathrm{C}_{5^{-}}$Poverty and seeks self-respect
$\mathrm{C}_{6}$ - Drug alcohol and tobacco use
$\mathrm{C}_{7}$-Violence on mass media / violent video games
$\mathrm{C}_{8}$ - Increasing aggressive behavior.

As the data is an unsupervised one and involves lot of uncertainties we are justified in using BANCM to analyses the problem of youth violence.

$$
\begin{gathered}
{\left[\begin{array}{ccccccc}
1 & 0 & 3 & -2 & -3 & 5 & 4 \\
2 & -1 & 1 & 0 & -3 & 2 & 3 \\
3 & 1 & 4 & 2 & 1 & 0 & -4 \\
0 & -3 & 3 & 0 & -2 & -3 & -2 \\
-1 & 2 & 5 & 3 & 2 & -2 & 0 \\
0 & -4 & 2 & 1 & -3 & 0 & 4 \\
-2 & 0 & 3 & 1 & 0 & -2 & 3 \\
-4 & 3 & 2 & 0 & 4 & 0 & -1
\end{array}\right] \cup\left[\begin{array}{cccccccc}
0 & 1 & 0 & 1 & 0 & 1 & 0 & 1 \\
0 & 0 & I & 1 & 0 & 0 & 1 & 0 \\
0 & 1 & 0 & 0 & 0 & 0 & 0 & 1 \\
0 & 1 & 0 & 0 & 1 & 0 & 0 & 0 \\
1 & 0 & 0 & 1 & 0 & 0 & 0 & 0 \\
0 & 0 & 0 & 0 & 1 & 0 & 0 & 0 \\
0 & 0 & 0 & 0 & 0 & 0 & 0 & 1 \\
0 & 0 & 0 & 1 & 0 & 0 & 0 & 0
\end{array}\right]} \\
\mathrm{E}=\mathrm{E}_{1}
\end{gathered}
$$

Let the initial vector $\mathrm{X}_{1}$ in BANCM

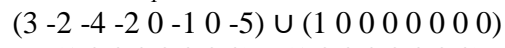

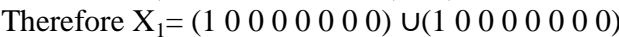

The effect $\mathrm{X}_{1}$ on the dynamical system $\mathrm{E}$

$$
\begin{aligned}
& \mathrm{X}_{1} \mathrm{E}=\left(\begin{array}{llllllll}
1 & 0 & 0 & 0 & 0 & 0 & 0 & 0
\end{array}\right) \mathrm{E}_{1} \cup\left(\begin{array}{llllllll}
1 & 0 & 0 & 0 & 0 & 0 & 0 & 0
\end{array}\right) \mathrm{E}_{2}
\end{aligned}
$$

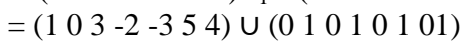

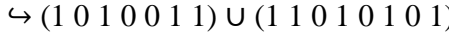

$$
\begin{aligned}
& \Rightarrow\left(\begin{array}{llllllll}
1 & 0 & 1 & 0 & 0 & 1 & 1
\end{array}\right) \mathrm{E}_{1}^{\mathrm{T}} \mathrm{U}\left(\begin{array}{lllllll}
1 & 1 & 0 & 1 & 0 & 1 & 01
\end{array}\right) \mathrm{E}_{2}
\end{aligned}
$$

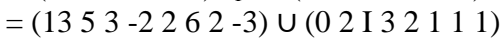

$$
\begin{aligned}
& \hookrightarrow\left(\begin{array}{llllllll}
1 & 1 & 1 & 0 & 1 & 1 & 1 & 0
\end{array}\right) \cup\left(\begin{array}{llllllll}
1 & 1 & \mathrm{I} & 1 & 1 & 1 & 1 & 1
\end{array}\right)=\mathrm{X}_{2}
\end{aligned}
$$

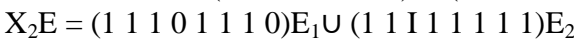

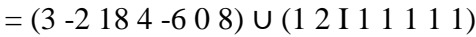

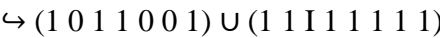

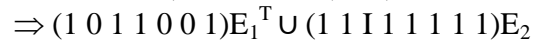

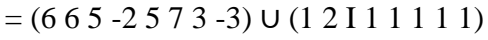

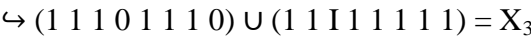

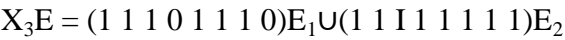

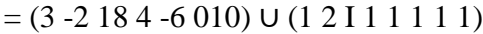

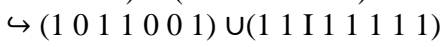


Now $X_{2}=X_{3}$. Hence the limit points is $\left(\begin{array}{llllllll}1 & 1 & 1 & 0 & 1 & 1 & 1 & 0\end{array}\right),\left(\begin{array}{llll}1 & 0 & 1\end{array}\right.$

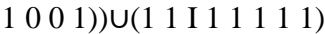

The set of all limit points corresponding to the different input vectors

\begin{tabular}{|c|c|c|}
\hline No & $\begin{array}{c}\text { Input } \\
\text { Vector }\end{array}$ & Limit points \\
\hline 1 & $(10000000)$ & 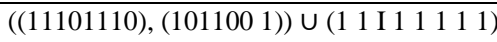 \\
\hline 2 & $(01000000)$ & 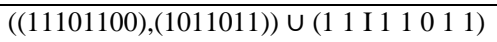 \\
\hline 3 & $(00100000)$ & 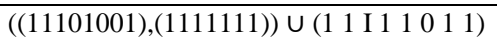 \\
\hline 4 & $(00010000)$ & 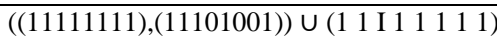 \\
\hline 5 & $(00001000)$ & 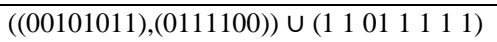 \\
\hline 6 & $(00000100)$ & 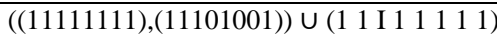 \\
\hline 7 & $(00000010)$ & 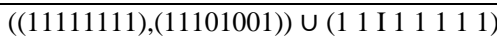 \\
\hline 8 & $(00000001)$ & 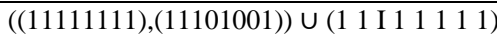 \\
\hline
\end{tabular}

\section{Conclusion}

We analyzed the causes of youth violence using BANCM, the set of all limit points are highlighting that $\mathrm{A}_{1}, \mathrm{~A}_{2}, \mathrm{~A}_{3}, \mathrm{~A}_{5}, \mathrm{~A}_{6}$ $\mathrm{A}_{8}, \mathrm{~B}_{1}, \mathrm{~B}_{3}, \mathrm{~B}_{4}, \mathrm{~B}_{6}, \mathrm{~B}_{7}, \mathrm{C}_{1}, \mathrm{C}_{2}, \mathrm{C}_{4}, \mathrm{C}_{5}, \mathrm{C}_{7}$ and $\mathrm{C}_{8}$ are the main causes and effects of youth violence. i.e., The effect of Poor family functioning, Academic failure / dropping out of school, Delinquent peers / gang membership, Castesam / inequality, Influences of mass media and Prizes hike in the basic needs, Parental criminality / Domestic violence, Poverty and seeks self-respect and Violence on mass media / violent video games are leads to Audit for drugs and alcohol, Involving in other forms of anti-social behavior such as terrorism, robbery etc., Murdering / fake encounter, Run away from home and Increasing aggressive behavior but Ill treatment by teacher is an indeterminate position.

\section{Parent's responsibility to protect their children from violence}

1. Parents have to talk to their teen, and listen - show caring and concern know where teens go, what they do, and whom they're with.

2. We Include teens in family activities, and be home during at least one of these times: when our teen wakes up, when he or she comes home from school, at dinner time, or when our teen goes to bed. discipline

3. Be consistent and firm - but not harsh - in our

4. If applicable, help our teen or other family members get help for drug or alcohol problems.

5. Monitor and control our teen's exposure to violence in the media, including television, movies, video games, music, etc.

6. Parents should get more involvement in their community and their child's school; talk to school administrators about violence or bullying that occurs at school.

7. Parents should be a good example of non-violent ways to resolve conflicts

\section{Future Direction}

The violence due to aggressive behavior and family condition are correlated. The broken families are the fertile nurseries for the anti-social behavior among the children. Family plays a vital role in formation of mental and psychic abilities of children. Family is placed at the centre of great struggle between good and evil, between life and death, between love and all that is opposed to love. Hence parents have a greater role in shaping educating the next generation in to a society in to a peaceful society. We planned to study the behavior of parents in influencing the children in to violent behavior. .

\section{REFERENCES}

[1] Axelrod, R. (1976). Structure of decision: The cognitive maps of political elities. Princeton, NJ: Princeton University Press.

[2] Kosco, B. (1986), "Fuzzy Cognitive Maps" International journal of man-machine studies, January, 62-75

[3] Kosco, B.,( 1997) "Neural Networks and Fuzzy Systems: A Dynamical Systems Approach to Machine Intelligence", Prentice Hall of India,

[4] Lian-Hua Chen "Violent Scene Detection in Movies: World Scientific Journal.

[5] Strauss M.A , 2007 "Conflict Tactics Scales. In: NA. Jackson, editor Encyclopedia of Domestic violence”,.

[6] Thirusangu et.al. (2012) "A new bidirectional associative fuzzy cognitive dynamical system". Indian Journal of Science and Technology,.

[7] Vasantha Kandasamy W.B and Smarandache Florentin (2004) "Analysis of social aspects of migrant laborers living with HIV/AIDS using Fuzzy Theory and Neutrosophic Cognitive Maps", Xiquan, Phoenix.

[8] Vasantha Kandasamy W.B and Smarandache Florentin, "Fuzzy Cognitive Maps and Neutrosophic Cognitive Maps", Xiquan, Phoenix (2003)

[9] Varma, D. Chandra, PS, Thomas, T. Carey, MP. (2007) "Intimate partner violence and sexual coercion among pregnant women in India: Relationship with depression and post traumatic stress disorder". J Affect Disord; 102:227-35.

[10] Victor Devadoss, A. Felix, A. (2012), "Fuzzy Clustering of the Domestic Violence for the Degree of Suicide thought based on Married Women Perception". International Journal of Engineering Research and Application.

[11] Victor Devadoss, A. Clement Joe Anand, M. Felix, A. (2012); "A Study on the Impact Violent Video-Games playing among Children in Chennai using Neutrosophic Cognitive Maps". International Journal of Scientific \& Engineering Research.

[12] Zimmermann H.J (2011), "Fuzzy Set Theory and its application", Fourth Edition Springer. 